\title{
Dormir, talvez sonhar: temporalidade, percepção e resistência
}

CRARY, J.

24/7 - Capitalismo

tardio e os fins do sono.

São Paulo: Cosac Naify,

144 p., 2014.

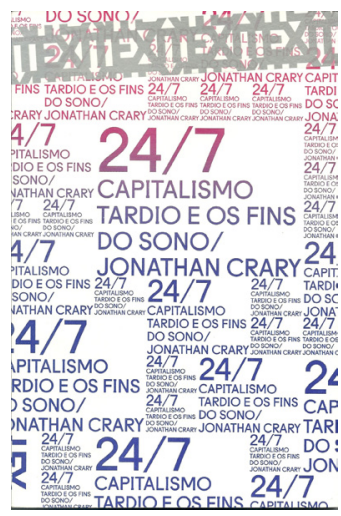

Resumo: O livro de Jonathan Crary faz uma crítica à lógica de funcionamento contínuo do capitalismo contemporâneo, que tem colonizado os modos de percepção e experiência do homem. O sono é apontado como signo de resistência ao fundamentalismo mercantil, por ser a possibilidade de fissurar as temporalidades homogêneas com as quais os ciclos de produção e consumo regulam nossas vidas.

Palavras-chave: capitalismo; tempo; visibilidade; controle; experiência.

Abstract: Sleeping, maybe dreaming: tempo, perception and resistence - Jonathan Crary's book criticizes the continuous operation of the logic of contemporary capitalism, which has been colonizing the modes of human perception and experience. The sleep is pointed out as a resistance sign to the market fundamentalism, being able to crack the homogeneous temporality of the production and consumption cycles that regulate our lives.

Palavras-chave: capitalism; time; visibility; control; experience. 
Jonathan Crary é teórico da cultura visual, professor da Universidade de Columbia, EUA. O título de seu livro, de caráter ensaístico e inspiração marxista, "24/7 Capitalismo Tardio e os Fins do Sono" já demonstra o centro de sua crítica - o fundamentalismo econômico capitalista que rege a lógica de um mundo em funcionamento contínuo, produzindo e consumindo 24 horas por dia, 7 dias por semana, 365 dias por ano. Nesse mundo é preciso estar em atividade todo o tempo, mesmo que essa atividade seja um rodar no vazio, uma incessante produção de vigilância e controle, já que estar ativo é, inextrincavelmente, tornar visível tal atividade. Um mundo sem descanso, sem tempo livre, sem férias, mas ainda não sem sono. Por enquanto. E é por isso que o autor vê no sono o último reduto de resistência à regulação da vida.

Meu principal argumento é que, no contexto de nosso próprio presente, o sono pode representar a durabilidade do social, e que o sono pode ser o análogo de outros limiares nos quais a sociedade poderia defender ou proteger-se a si mesma. Como o estado mais privado e vulnerável de todos, o sono depende crucialmente da sociedade para se sustentar (CRARY, 2014, p. 34).

Dividido em quatro capítulos, a primeira imagem formulada pelo autor é da migração de certos pássaros da América do Norte, que chegam a ficar dias acordados até alcançar seu destino. Exemplo fascinante para pesquisas militares em busca do soldado sem sono e porque não, do consumidor sem sono. Crary disserta sobre a degradação da vida pela preponderância do tempo produtivo e econômico. Seleciona exemplos que podem parecer fenômenos excepcionais, mas garante que já seriam condições normativas em muitos lugares. A argumentação do autor é desenvolvida para nos alertar do alto custo humano a sustentar o mundo 24/7.

Por isso mesmo Jonathan Crary defende sua tese de que o sono precisa continuar sendo preservado porque pode atuar como alternativa à lógica mercantilista. $\mathrm{O}$ sono como o último reduto ainda a salvo da captura dos dispositivos de poder. A perda do sono representaria o esmagamento das subjetividades, o enfraquecimento da categoria da possibilidade, uma diminuição da criação de outros mundos possíveis, como sempre vislumbramos nos sonhos que acontecem quando estamos dormindo.

O mundo sem sombras da globalização neoliberal, onde não há temporalidades alternativas é também um mundo de indiferença: luminosidade e escuridão; ação e repouso; justiça e terror; público e privado - tudo torna-se equivalente. Conceitos antagônicos que se encontram indistintos no universo 24/7. Não surpreende, portanto, que todas as referências encontrem-se em crise e o que deveria ser partilhado, o mundo em comum, perceba-se em declínio.

Para falar sobre o esgotamento do sentido de comunidade e de bem comum, o teórico traz como referências Jean-Luc Nancy e Hannah Arendt. O livro "A Condição Humana", de Arendt, colabora para pensar sobre como pode ser prejudicial quando a esfera privada 
confunde-se com a pública, ameaçando, assim, o mundo comum e a vida política. No mundo 24/7, onde a visibilidade torna-se parâmetro - e mesmo quando algo deveria estar protegido e preservado de olhares alheios, nada escapa à transparência midiatizada -, as noções de compartilhamento e de produção do comum estão completamente deturpadas. Toda experiência é filtrada de modo a servir ao mercado. Somos resumidos a perfis de consumidores e nossas máquinas, aparentemente a nosso serviço, nos oferecem a todo tempo oportunidades imperdíveis sobre o que consumir e para onde viajar, sempre de acordo com os dados disponibilizados na rede. E parece ser sempre nela que está algo mais interessante que a nossa própria vida vivida cotidianamente.

O cotidiano e a sazonalidade aparecem como noções incompatíveis com a atual escala de acumulação do capitalismo e a ordem tecnológica contemporânea, já que "hoje não haveria um só instante na vida dos indivíduos que não seja modelado, contaminado ou controlado por algum dispositivo" (AGAMBEN apud CRARY, 2014, p. 55). O italiano Giorgio Agamben aparece como mais um interlocutor de Crary no projeto de persuadir o leitor de que estamos cada vez mais sujeitos às diretrizes do poder, aceitando "práticas e mecanismos (...) que têm o objetivo de fazer frente a uma urgência e de obter um efeito mais ou menos imediato" (AGAMBEN, p. 35), efeito este de administração e controle das pessoas e suas capacidades perceptivas. Resistindo aos imperativos de consumo e atuando como uma barreira à atuação desses dispositivos estaria o sono, ainda não colonizado pelo sistema capitalista.

É importante levar em consideração que, apesar da análise de Crary recair, sobretudo, sobre as formas contemporâneas de controle do capitalismo, o autor faz questão de alertar que não se trata de um estado de coisas inaugurado apenas na passagem do século XXI. Ele abre o terceiro capítulo com a imagem do quadro de Joseph Wright, Os moinhos de algodão de Arkwright à noite, de 1782, para indicar o começo da temporalidade 24/7 já nos finais do século XVIII, com o início da industrialização, a iluminação artificial, o trabalho em turnos e uma redefinição dos ciclos naturais, a partir da necessidade de produção capitalista.

O pós-guerra é identificado também como um momento histórico decisivo no impacto das experiências sensoriais e perceptivas. Por isso, o autor convoca Gilles Deleuze quando fala da passagem da sociedade disciplinar para as "sociedades de controle" logo depois da II Guerra Mundial. Nas sociedades de controle a internalização dos efeitos de comando e normalização se efetivam de maneira ainda mais eficiente, já que o autor francês considerava a disciplina como um molde e o controle como uma modulação, nunca pronta, mas sempre operando como um regime disperso de dominação. Porém, para Crary, não há uma passagem completa de um tipo de sociedade à outra, mas a convivência de modelos inspirados em ambos os modos de regulação social.

A difusão em massa da televisão, nos anos 1950, é indicada como uma drástica transformação das temporalidades vividas. A TV teria sido o primeiro aparelho que 
causaria uma espécie de anestesia e desengajamento político, através do advento dos padrões semiautomático de comportamento e destituição do tempo. Nos anos 1990, com o advento dos primeiros computadores pessoais o impacto nesse sentido seria ainda maior, apontando para um empobrecimento sensorial e um embotamento da percepção.

O último capítulo é dedicado, em grande parte, à análise de obras artísticas como o filme "La Jetée" (1962) de Chris Marker e o romance "O Caçador de Androides" (1968) de Philip K. Dick. As obras são examinadas à luz das mudanças perceptivas e espaço-temporais da sociedade dos anos 1960. Obras que, de alguma forma, trazem à tona o colapso não apenas ambiental como também social; mundos catastróficos que se desenham ficcionalmente. $\mathrm{O}$ autor usa desses exemplos para explicitar o quanto nos passa despercebido que vivemos nesse mesmo mundo, mantendo a ilusão de que estamos descolados dessa realidade, "indiferentes à fragilidade e à transitoriedade das coisas vivas" (CRARY, 2014, p. 110). Ao mesmo tempo, ambas as obras nos remetem também à relevância da imaginação para a sobrevivência coletiva.

E é neste ponto que reside a grande inspiração do livro. O sono, através do sonho, estaria atrelado à capacidade de imaginar. Capacidade fortemente atacada no processo de modernização, como demonstra Crary. O sonho, sobretudo em sua concepção transindividual, vem sofrendo descrédito das novas indústrias de imagens desde o século XIX, gerando, por exemplo, uma liquidificação das manifestações dos anos 1960, com o esvaziamento político de suas propostas e a desvalorização da potência de uma imaginação coletiva. "No último quarto de século, o comunitário tem sido apresentado como o pior dos pesadelos" (CRARY, 2014, p. 123). Assim, qualquer alternativa a um modelo privatizado da vida é considerada inviável pelas formas de controle contemporâneas.

O teórico, então, retoma textos fundamentais dos anos 1960 como "Crítica da Razão Dialética" de Jean Paul Sartre e "A Sociedade do Espetáculo" de Guy Debord para falar de possibilidades coletivas de ação política, tendo em vista os atos insurrecionais que vem ocorrendo desde 2011 no mundo todo, inclusive no Brasil. Crary conclama Debord para lembrar do vínculo entre as palavras "comunidade" e "comunicação", e como o espetáculo atuaria para desarticular o sentido de encontro presente em tais conceitos. Na contramão de muitos ativistas, o autor questiona duramente a real capacidade política das mídias sociais e pergunta: "quais são os encontros que podem levar a novas formações, a novas capacidades de insurgência, e podem ocorrer - em quais espaços e temporalidades?" (CRARY, 2014, p. 129).

Jonathan Crary não parece muito otimista em relação "ao potencial revolucionário das mídias sociais". Mas aqui e ali conseguimos apreender que não se trata exatamente de um completo descarte das maneiras de se relacionar da contemporaneidade. Trata-se de não sermos reduzidos a isso. Elas apenas serão realmente efetivas se atuarem como plataforma de encontros para além do ciberespaço.

Para encerrar seu livro o autor muda de tom, nos apresentando algumas poucas obras nas quais reconhece o desejo de fissurar as temporalidades achatadas e reativar 
capacidades perceptivas, como o filme "Do Leste" (1993) de Chantal Akerman, cuja estratégia é recuperar o tempo da espera em lugares em que a lógica capitalista ainda não havia chegado. Um lugar onde ainda existia um tempo comum de compartilhamento. Um lugar onde ainda havia o tempo da brincadeira sem finalidade, um tempo de contemplação.

E é no sono e no sonho que Crary aposta todas as suas fichas, numa espécie de suspensão do tempo necessário para que devaneios e utopias possam nascer. Na possibilidade de ativação de um futuro que se afaste da catástrofe que o sistema capitalista tem produzido, tanto pelas extremas desigualdades sociais, quanto pelos desastres ambientais. O sono aparece como uma possibilidade de repensar as questões políticas, e acionar novos modos de vida.

Talvez (...) a imaginação de um futuro sem capitalismo comece como um sonho. Seriam insinuações do sonho como interrupção radical, como recusa do peso impiedoso do nosso presente global, do sono que, no nível mais mundano da experiência cotidiana, pode sempre esboçar os contornos de renovações e começos mais plenos de consequências (CRARY, 2014, p. 137).

Jonathan Crary nos convida a sonhar com um mundo melhor. E mesmo que isso possa soar ingênuo, parece tarefa urgente para encontrar a saída quando estivermos acordados. Durmamos.

Fernanda Raquel doutoranda do PPG em Comunicação e Semiótica da PUC/SP; é bolsista Fapesp e pesquisadora do Centro de Estudos Orientais, PUC/SP.

fe.raquel@globo.com

\section{Referências}

AGAMBEN, G. O que é um dispositivo? In: O que é o contemporâneo? E outros ensaios. Chapecó: Argos, 2009. 